Vol. XXII, No. 2

\title{
Bird Photography
}

by Hans S. Dommasch, Medical Photography Department, University of Saskatchewan, Saskatoon

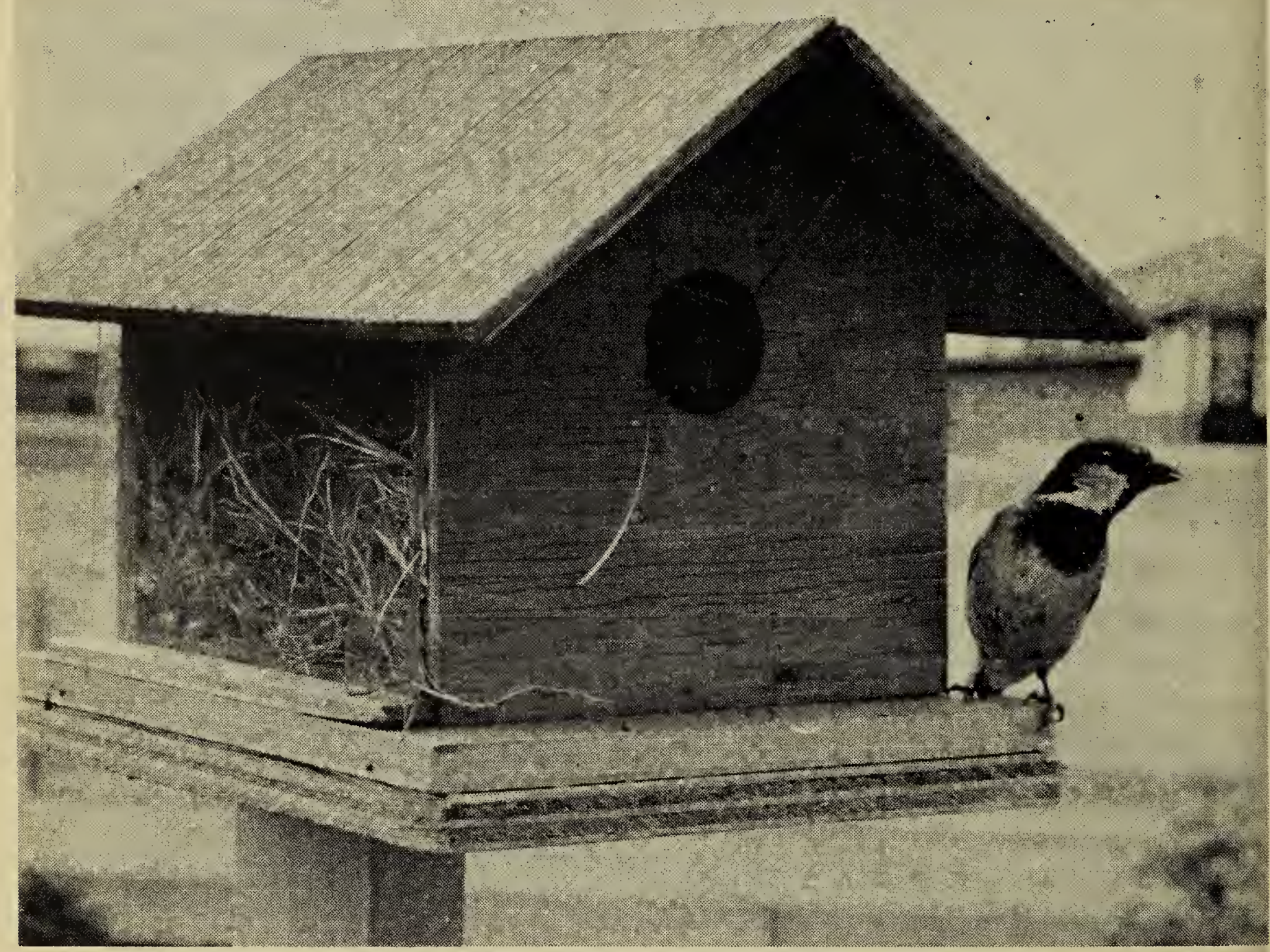

Male House Sparrow at nest site. Notice glass plate at left side.

Bird photography is a lot of fun. Blue Jay readers, who are interested in nature, have a real advantage because their knowledge of the subject to be photographed simplifies the picture-taking process. They are well enough acquainted with the behaviour, markings and nesting sites of the birds to know what to photograph and where to find itheir subject. Next, however, you have to learn how to handle a camera and to master a few little tricks to help you outsmart your little subjects! The easiest way to take bird pictures is to watch for activity in and about the nest.

For phctographing birds, you need a camera, firm tripod, and remote control release. I use an air release which has a rubber bulb on one end, and a plunger which is secured into the cabie release socket of the camera, at the other. The shutter can be tripped when the rubber bulb is squeezed at the farther end of the connecting tubing. The connecting tubing is 30-40 feet long. The air release can be bought for a few dollars at most camera stores.

To photograph birds close at hand in an interesting activity, you should locate a nest. You can even provide this nest. Put up a bird house in your backyard and for better observation have it built so that you can take out one side and replace it with a glass plate, which, when put in from time to time, will allow you to watch the progress in the nest.

Now you are ready for your bird photographs. If no other bird moves into the house, the House Sparrow will be most obliging. The camera can be set on a tripod and the air release will allow you to operate the camera many feet away from the nest. Besides getting pictures you will observe that the male sparrow is much 
more active in the nest building than his female companion. I think this speaks well of the male!

Another good place for trying your first bird photographs would be at a bird bath or feeder. If you should find a nest in a tree, the camera can be set on a step ladder or clamp tripod which can be fastened to another tree or branch. Again the air release will allow you to move away from the camera and still be able to release the shutter at will.

At the beginning of bird photography, start with easy subjects near at hand, like sparrows, robins, killdeers. When you have more experience in the technique, you can concentrate on photographing rarer specimens. If you find a photogenic subject take plenty of photographs of it. You never know, your last picture might be the best. From the very first day of taking photographs you will learn a great deal about your subject and your skill will increase.

Besides the fun of picture taking, you will also take on responsibilities. When you find a nest you become responsible for the well being of the feathered tenants. We know that no bird picture is worth the taking if it means the death of the nestlings. Precautions have to be taken to protect the young both during and after the picture taking session. Careless destruction of the protective nest cover will reveal the young birds to predators and merciless exposure to the hot sun will quickly kill them. DO NOT BREAK BRANCHES-they should be tied out of the camera's view. Prolonged photographic sessions should be confined to overcast days so that the young featherless birds will not be exposed to the scorching rays. Patience and planning are the keys to fine bird photography; good pictures are not snapped-they are planned.

If you observe these few suggestions, you will find that shooting with the camera will bring much more pleasure than hunting with a gun.

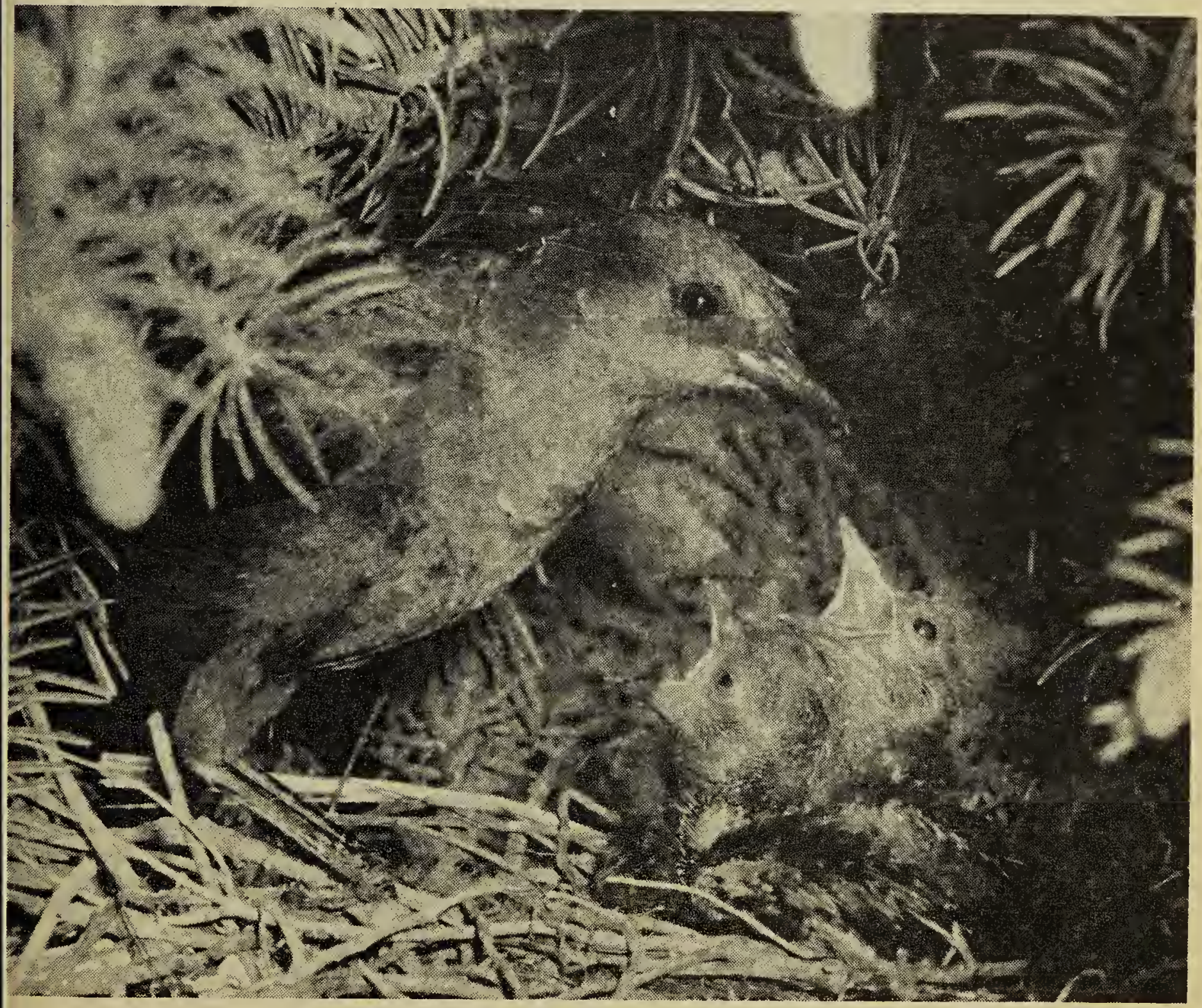

Female Brewer's Blackbird with nestlings. 


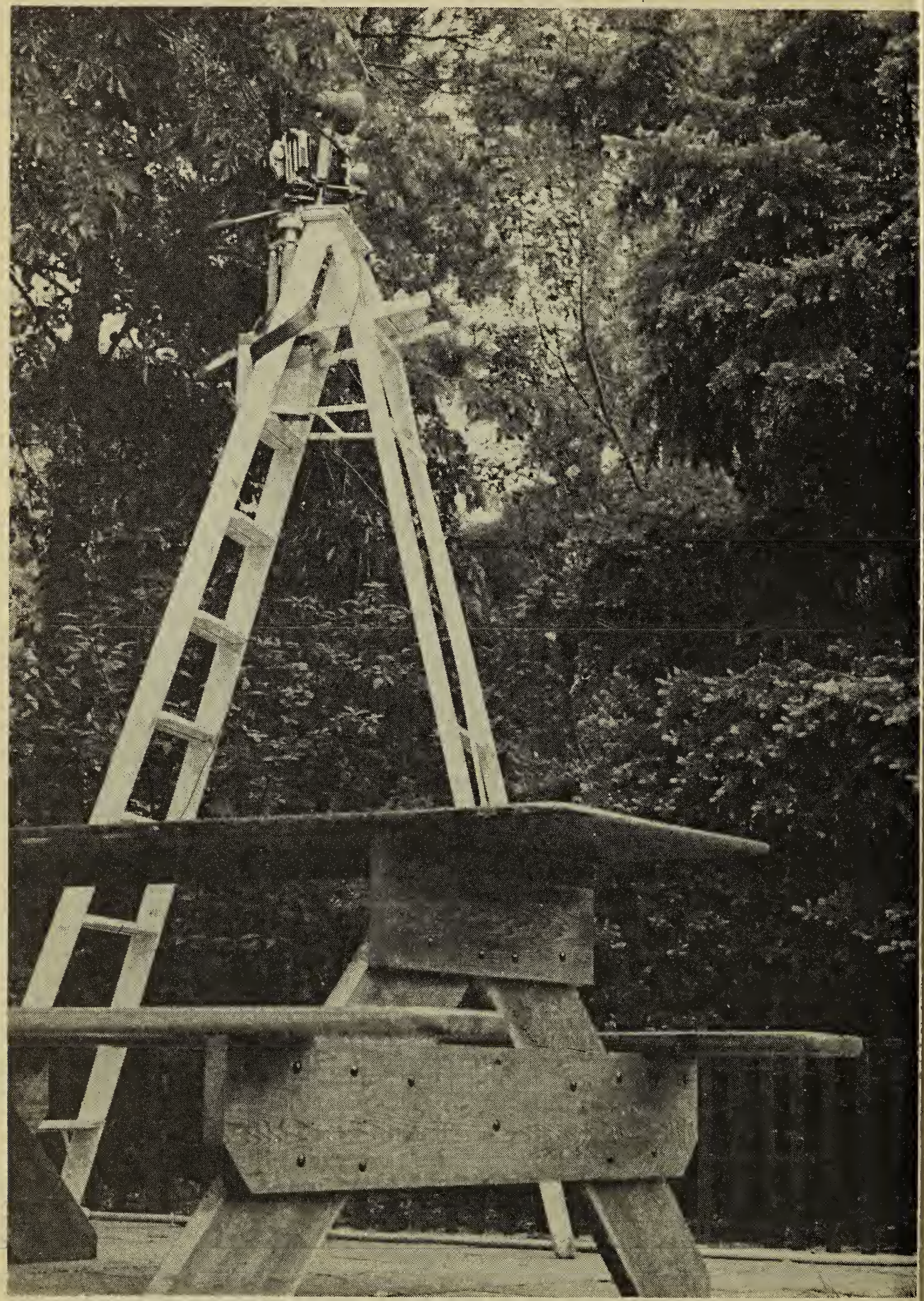

Photo by Hans S. Dommasch

Comero on twelve foot stepladder ready for remote control air release pictures of Brewer's Blackbirds shown on the previous page and on the front cover. 